\title{
RETRACTED ARTICLE: Two efficient algorithms for a quay crane scheduling and assignment problem
}

\author{
R. Tavakkoli-Moghaddam • F. Taheri · M. Bazzazi • \\ S. Salahi
}

Received: 12 October 2008 / Accepted: 22 January 2010 / Published online: 11 February 2010

(C) Springer Science+Business Media, LLC 2010

This article has been withdrawn due to the fact that almost

the identical article was published in another journal.

R. Tavakkoli-Moghaddam ( $\varangle$ )

Department of Industrial Engineering and Center of Excellence

for Intelligent Based Experimental Mechanics, College of

Engineering, University of Tehran, Tehran, Iran

e-mail: tavakoli@ut.ac.ir

F. Taheri · M. Bazzazi

Department of Industrial Engineering, Mazandaran University

of Science and Technology, Babol, Iran

\section{S. Salahi}

Department of Industrial Engineering, Islamic Azad University-

Science and Research Branch, Tehran, Iran 